\title{
Elevated expression of CDK4 in lung cancer
}

\author{
Aibing $\mathrm{Wu}^{1 \dagger}$, Bin $\mathrm{Wu}^{2 \dagger}$, Jinsong Guo ${ }^{6 \dagger}$, Weiren $\mathrm{Luo}^{1}$, Dong $\mathrm{Wu}^{2}$, Huiling Yang ${ }^{4}$, Yan Zhen ${ }^{1}$, Xiaoli Yu', Hao Wang ${ }^{1}$, \\ Ying Zhou', Zhen Liu ${ }^{3 *}$, Weiyi Fang ${ }^{1 *}$ and Zhixiong Yang ${ }^{5^{*}}$
}

Background: The aim of the present study was to analyze the expression of Cyclin-dependent kinase 4 (CDK4) in lung cancer and its correlation with clinicopathologic features. Furthermore, the involvement of CDK4-mediated cell cycle progression and its molecular basis were investigated in the pathogenesis of lung cancer.

Methods: Using immunohistochemistry analysis, we analyzed CDK4 protein expression in 89 clinicopathologically characterized lung cancer patients (59 males and 30 females) with ages ranging from 36 to 78 years and compared them to 23 normal lung tissues. Cases with cytoplasmic and nuclear CDK4 immunostaining score values greater than or equal to 7 were regarded as high expression while scores less than 7 were considered low expression. The correlation between the expression level of CDK4 and clinical features was analyzed. Furthermore, we used lentiviral-mediated shRNA to suppress the expression of CDK4 and investigate its function and molecular mechanism for mediating cell cycle progression.

Results: The expression level of CDK4 protein was significantly increased in lung cancer tissues compared to normal tissues $(P<0.001)$. In addition, high levels of CDK4 protein were positively correlated with the status of pathology classification $(P=0.047)$, lymph node metastasis $(P=0.007)$, and clinical stage $(P=0.004)$ of lung cancer patients. Patients with higher CDK4 expression had a markedly shorter overall survival time than patients with low CDK4 expression. Multivariate analysis suggested the level of CDK4 expression was an independent prognostic indicator $(P<0.001)$ for the survival of patients with lung cancer. Use of lentiviral-mediated shRNA to inhibit the expression of CDK4 in lung cancer cell line A549 not only inhibited cell cycle progression, but also dramatically suppressed cell proliferation, colony formation, and migration. Furthermore, suppressing CDK4 expression also significantly elevated the expression of cell cycle regulator p21

Conclusion: Overexpressed CDK4 is a potential unfavorable prognostic factor and mediates cell cycle progression by regulating the expression of $p 21$ in lung cancer

\section{Background}

Lung cancer is the world's most prevalent cancer according to the World Health Organization, with 1.2 million new cases every year. Nearly all lung cancers arise due to smoking and men are more frequently diagnosed than women. However, a rise in female smoking worldwide has started reversing the trend.

In China, about 300,000 lung cancer patients (23/ $100,000)$ are diagnosed each year [1]. Unfortunately, most

\footnotetext{
*Correspondence: narcissus_jane@163.com; fangweiyi1975@yahoo.com.cn; yangzhixiong@126.com

† Contributed equally

${ }^{1}$ Cancer Research Institute of Southern Medical University, 510515,

Guangzhou, PR China

${ }^{3}$ Department of Pathology, Medical College of Guangzhou, 510450,

Guangzhou, PR China

Full list of author information is available at the end of the article
}

lung cancer patients tend to present with an advanced stage of disease due to its deep location within the lungs and lack of symptoms during early stages. This may contribute to the overall poor prognosis of most lung cancer patients. Therefore, it is of great interest to identify factors which provide early diagnosis, more accurate prognosis prediction, and allow development of novel therapeutic strategies.

Genetic abnormalities found in lung cancer typically affect two general classes of genes: oncogenes and tumor suppressors. Cancer-promoting oncogenes are typically activated in cancer cells, giving those cells new properties, such as hyperactive growth and division, protection against programmed cell death, or loss of respect for normal tissue boundaries. CDK4 is part of the cyclin-dependent kinase family. The protein encoded by this gene is a member of

\section{Biomed Central}


the Ser/Thr protein kinase family and is highly similar to the gene products of S. cerevisiae cdc28 and S. pombe cdc2. It is a catalytic subunit of the protein kinase complex important for G1 cell cycle progression. Transition through G1-S phases, is controlled by the regulatory subunits D-type cyclins $(C D K 4$ and $C D K 6)$ and $C D K$ inhibitor p16(INK4a). Marval et al. found that CDK4 has higher oncogenic activity than cyclin D1(CCND1) and it markedly enhanced malignant skin tumorigenesis in CDK4 transgenic mice [2]. Furthermore, overexpression of $C D K 4$ has been showed in many tumor types, including oral squamous cell carcinoma [3], pancreatic endocrine tumors [4], lung cancer [5,6], and nasopharyngeal carcinoma [7], suggesting that $C D K 4$ is a key factor in promoting the initiation and development of tumors.

In order to clarify the role of $C D K 4$ in the pathogenesis of lung cancer, we explored the correlation of its protein expression with clinicopathologic features of lung cancer patients. We found that the expression levels of CDK4 were higher in lung cancer tumors compared to those in normal lung tissues. This increased CDK4 expression was associated with the progression and poor prognosis of lung cancer patients. Furthermore, suppressing the expression of CDK4 elevated tumor suppressor $p 21$ expression, which may function to reduce cell proliferation and migration.

\section{Materials and methods}

\section{Sample collection}

Eighty-nine (89) paraffin-embedded lung cancer and 23 normal lung samples were obtained from the First Affiliated Hospital of Guangdong Medical School, Zhanjiang City, China. In the 89 lung cancer cases, there were 59 males and 30 females with ages ranging from 36 to 78 years. The clinical follow-up time of patients ranged from 6 to 55 months. For use of these clinical materials for research purposes, prior consent from the patients and approval from the Ethics Committees of this hospital was obtained. Histological classification and clinicopathologic staging of the samples were performed according to the rules of according to the WHO histologic classification.

\section{Immunohistochemistry}

Paraffin sections $(4 \mu \mathrm{m})$ from samples were deparaffinized in $100 \%$ xylene and re-hydrated in descending ethanol series and water according to standard protocols. Heatinduced antigen retrieval was performed in $10 \mathrm{mM}$ citrate buffer for $2 \mathrm{~min}$ at $100^{\circ} \mathrm{C}$. Endogenous peroxidase activity and non-specific antigen were blocked with peroxidase blocking reagent containing 3\% hydrogen peroxide and serum, followed by incubation with goat anti-human CDK4 antibody (1:100) (Santa, MA, USA) for overnight at $4^{\circ} \mathrm{C}$. After washing, the sections were incubated with biotin-labeled rabbit anti-goat antibody for $10 \mathrm{~min}$ at room temperature, and subsequently were incubated with streptavidin-conjugated horseradish peroxidase (HRP) (Maixin Inc, China). The peroxidase reaction was developed using 3, 3-diaminobenzidine chromogen solution in DAB buffer substrate. Sections were visualized with DAB and counterstained with hematoxylin, mounted in neutral gum, and analyzed using a bright field microscope.

\section{Evaluation of staining}

The immunohistochemically stained tissue sections were reviewed and scored separately by two pathologists blinded to the clinical parameters. Expression of CDK4 in the nucleus and in the cytoplasm was independently evaluated. For cytoplasmic staining, the score was evaluated according to the sum of cytoplasm staining intensity and the percentage of positive staining areas of cells. The staining intensity was scored as previously described(0-3) $[8,9]$ and the percentage of positive staining areas of cells was defined as a scale of 0 to 3 where 0 represents $<10 \%, 1$ is $10-25 \%, 2$ is $26-75 \%$, and 3 is $\geq 76 \%$. For nuclear staining, the staining score was defined based on the sum of nuclear staining intensity and the number of positive nuclear staining. Nuclear staining intensity score was consistent with cytoplasm and positive nuclear staining scores were defined as follows: 0 represents $<10 \%, 1$ is $10-50 \%, 2$ is $51-80 \%$, and 3 is $\geq 80 \%$. The sum of the cytoplasm and nuclear staining scores was used as the final staining score for CDK4 (0-12). For statistical analysis, a final staining score of 0 6 or 7-12 was respectively considered to be low or high expression.

\section{Establishment of lung cancer A549 cell line with stably expressing shRNA-CDK4}

We selected two sequences(CDK4 509: Sense:5' CGCGTCCCCGCATGTAGACCAGGACCTAAGTTCAAGAGACTTAGGTCCTGGTCTACATGCTTTTTGGAAAT 3' Antisense:5'CGATTTCCAAAAAGCATG TAGACCAGGACCTAAGTCTCTTGAACTTAGGTCCT GGTCTACATGCGGGGA 3') CDK4 1097 Sense:5'CGCG TCCCCGCAGCACTCTTATCTACATAATTCAAGAGATTATGTAGATAAGAGTGCTGCTTTTTGGAAAT 3'; Antisense:5'CGATTTCCAAAAAGCAGCACTCTTATCTACATAATCTCTTGAATTATGTAGATAAG AGTGCTGCGGGGA 3') for targeting the CDK4 gene using the BLOCK-It RNAi Designer (Invitrogen, Carlsbad, CA). The preparation of lentiviral vectors expressing human CDK4 short hairpin RNA (shRNA) was performed using the pLVTHM-GFP Lentiviral RNAi Expression System. Replication-incompetent lentivirus was produced by cotransfection of the pLVTHM/CDK4-shRNA expression vector and ViraPower packaging mix containing an optimized mixture of two packaging plasmids: psPAX2 and 
pMD2.G into 293FT cells. Lung cancer A549 cells were infected with lentiviral particles containing specific or negative control vectors and the single colony with strong GFP expression was selected to establish stable silencing cell lines. The total RNA of these cell clones was isolated, and the levels of CDK4 mRNA were measured using realtime PCR examination.

\section{Western blot Analysis}

Cells were lysed in RIPA Buffer $(50 \mathrm{mM}$ Tris- $\mathrm{HCl} \mathrm{pH}$ 8.0, 1 mM EDTA pH 8.0, $5 \mathrm{mM}$ DTT, 2\% SDS), and protein concentration was determined using BCA assay (Beyotime Inc, China). Total protein $(30 \mu \mathrm{g})$ was resolved using a $10 \%$ SDS-PAGE gel and electro-transferred to polyvinylidene fluoride membranes (Invitrogen, Carlsbad, CA), and blocked with 5\% nonfat dry milk in Tris-buffered saline, $\mathrm{pH}$ 7.5. Membranes were immunoblotted overnight at $4{ }^{\circ} \mathrm{C}$ with rabbit polyclonal anti$C D K 4$ antibody(1:500), anti- $A C T B$ antibody(1:400) and p21(1:200)(Santa Cruz Biotechnology, CA, USA). An HRP-conjugated anti-rabbit IgG antibody was used as the secondary antibody (Zhongshan Inc, China).

\section{Cell Proliferation}

Cell proliferation was analyzed using MTT assay (Sigma, St. Louis, USA). Briefly, $1 \times 10^{3}$ cells were seeded into a 96-well plate with quadruplicate repeat for each condition. After $24 \mathrm{~h}$ of incubation, MTT reagent was added to each well and incubated for $4 \mathrm{~h}$. The formazan crystals formed by viable cells were then solubilized in DMSO and measured at $490 \mathrm{~nm}$ for the absorbance (A) values. Each experiment was performed in triplicate.

\section{Colony Formation Assay}

About 100 cells were added to each well of a 6-well culture plate, and each cell group contained 2 wells. After 2 weeks of incubation, cells were washed twice with PBS and stained with Giemsa solution. The number of colonies containing $\geq 50$ cells was counted under a microscope. The colony formation efficiency was calculated as: efficiency $=$ (number of colonies/number of cells inoculated) $\times 100 \%$. Each experiment was performed in triplicates.

\section{Cell Cycle}

To evaluate cell cycle distribution, cells were seeded on $10 \mathrm{~cm}$-diameter plates in RPMI 1640 culture medium containing 10\% NBCS. After $48 \mathrm{~h}$ of incubation, a total of $1 \times 10^{6}$ cells were harvested, rinsed with cold PBS, and fixed with $70 \%$ ice-cold ethanol for $48 \mathrm{~h}$ at $4^{\circ} \mathrm{C}$. Fixed cells were rinsed with cold PBS followed by incubation with PBS containing $10 \mu \mathrm{g} / \mathrm{mL}$ propidium iodide and $0.5 \mathrm{mg} / \mathrm{mL}$ RNase A for $15 \mathrm{~min}$ at $37^{\circ} \mathrm{C}$. The DNA content of labeled cells was acquired using FACS
Caliber cytometry (BD Biosciences). Each experiment was performed in triplicates.

\section{In Vitro Cell Migration Assay}

Cells growing in the log phase were treated with trypsin and re-suspended as single-cell solution. A total of $1 \times 10^{5}$ cells were seeded on a fibronectin-coated polycarbonate membrane insert in a transwell apparatus (Corning Inc., Corning, NY). In the lower chamber, $600 \mu$ lof RPMI 1640 with $10 \%$ NBCS was added as chemoattractant. After the cells were incubated for $12 \mathrm{~h}$, the insert was washed with PBS, and cells on the top surface of the insert were removed by a cotton swab. Cells adhering to the lower surface were fixed with methanol, stained with Giemsa, and counted under a microscope in five predetermined fields $(\times 200)$. All assays were independently repeated at least three times.

\section{Expression examination of Cell cycle factors}

Changes in expression of cell cycle regulators $C D K 1$, $C D K 2, C D K 6, C C N D 1, p 15, p 16, p 21$, and $p 27$ were first detected by real-time PCR in pLVTHM/CDK4-shRNA and control expression vector. Subsequently, genes with markedly differential expression were further validated by western blot. Real-time PCR and western blot were carried out as described above.

\section{Statistical analysis}

All data were analyzed for statistical significance using SPSS 13.0 software. The Mann-Whitney U test was applied to the examination of relationship between CDK4 expression levels and clinicopathologic characteristics. Survival analysis was performed using KaplanMeier method. Multivariate Cox proportional hazards method was used for analyzing the relationship between the variables and patient's survival time. One-way ANOVA was used to determine the differences between groups for all in vitro analyses. A $P$ value of less than 0.05 was considered statistically significant.

\section{Results}

Immunohistochemical analysis of CDK4 protein expression in lung cancer and normal lung tissues

We measured the expression levels and subcellular localization of $C D K 4$ protein in 89 archived paraffin-embedded lung cancer samples and 23 normal lung tissues using immunohistochemical staining (Figure 1A-E). Specific $C D K 4$ protein staining was found in the cytoplasm and nucleus of normal and malignant lung tissues. Furthermore, we observed that in 50.6\% (45/89) of lung cancer samples, $C D K 4$ protein was highly expressed. In comparison, only $8.7 \%(2 / 23)$ of normal lung samples had highly expressed $C D K 4$ protein, significantly lower than that in the lung cancer samples $(P<0.001)$ (Table 1$)$. 

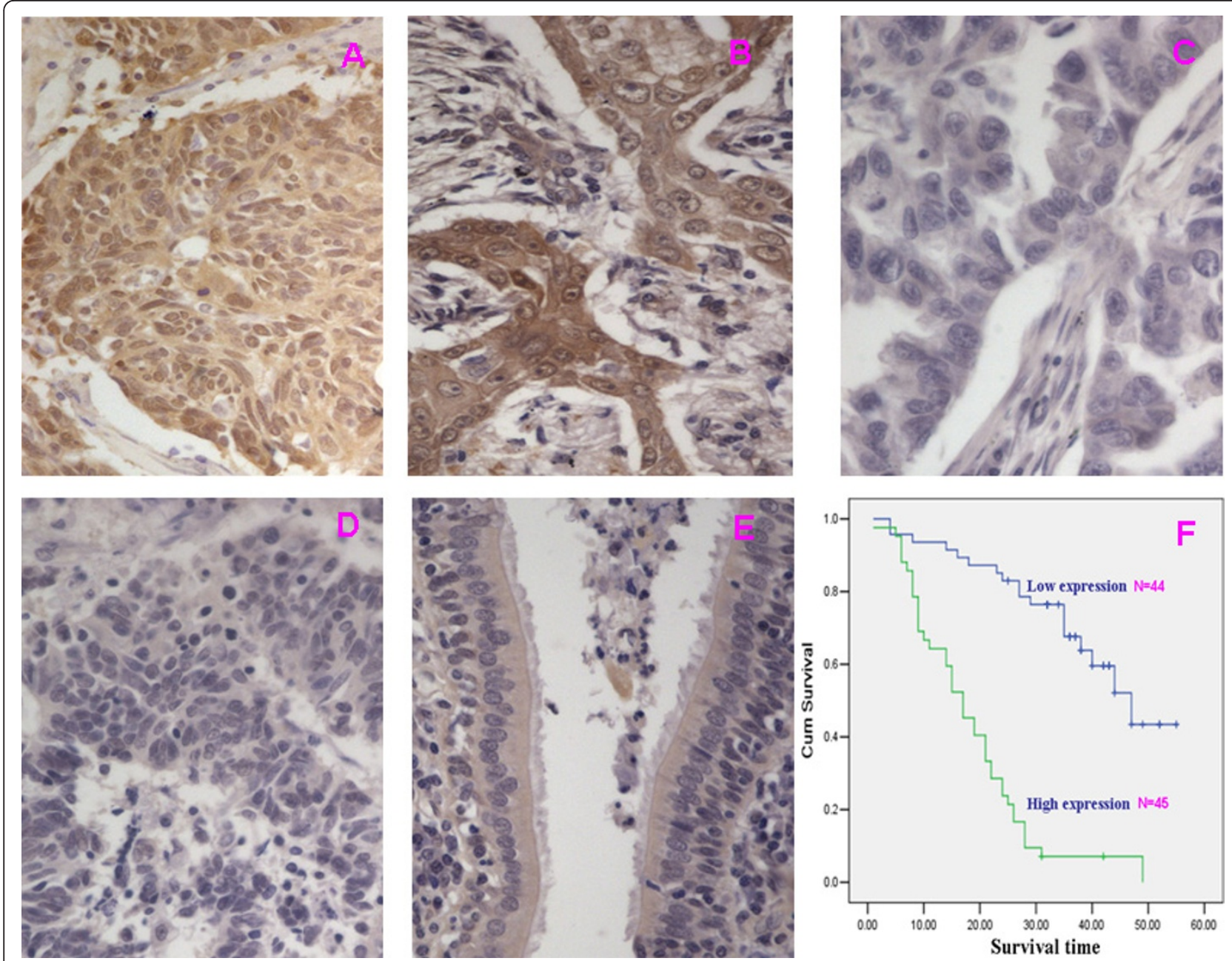

Figure 1 Expression of CDK4 protein predicts lung cancer patients' survival time. A and B: Strong expression of CDK4 in lung cancer samples; C and D: Weak expression of CDK4 in lung cancer sample; E:Weak expression of CDK4 in normal lung tissue. F. Kaplan-Meier survival analysis of overall survival duration in 89 lung cancer patients according to CDK4 protein expression. The log-rank test was used to calculate $p$ values.

\section{Relationship between clinicopathologic characteristics and CDK4 expression in lung cancer patients}

The relationship between clinicopathologic characteristics and CDK4 expression levels in individuals with lung cancer are summarized in Table 2 . We did not find a significant association of $C D K 4$ expression levels with patient's age, sex, smoking, degree of differentiation, tumor size ( $\mathrm{T}$ classification), or status of distant metastases (M classification) in 89 lung cases. However, we

Table 1 Protein expression of CDK4 between lung cancer and normal lung tissues

\begin{tabular}{|c|c|c|c|c|}
\hline \multirow[t]{2}{*}{ Group } & \multirow[b]{2}{*}{ Cases } & \multicolumn{2}{|c|}{ Protein expression } & \multirow[t]{2}{*}{$P$ value } \\
\hline & & High expression & Low expression & \\
\hline Cancer & 89 & $45(50.6 \%)$ & $44(49.4 \%)$ & \\
\hline Normal & 23 & $21(8.7 \%)$ & $2(91.3 \%)$ & 0.000 \\
\hline
\end{tabular}

observed that the expression level of CDK4 was positively correlated with the status of pathology classifica$\operatorname{tion}(P=0.047)$ lymph node metastasis (N classification) (N0-N1 vs. N2-N3) $(P=0.007)$, and clinical stage (I-II vs. III-IV) $(P=0.004)$ in lung cancer patients (Table 2$)$.

\section{Survival analysis}

To investigate the prognostic value of CDK4 expression for lung cancer, we assessed the association between the expression levels and patient survival using KaplanMeier analysis with the log-rank test. In 89 lung cancer cases with prognosis information, we observed that the level of $C D K 4$ protein expression was significantly correlated with the overall survival of lung cancer patients (Figure 1F). Patients with higher levels of CDK4 expression had poorer survival rates than those with lower levels of $C D K 4$ expression $(P<0.001)$. In addition, 
Table 2 Correlation between the clinicopathologic characteristics and expression of CDK4 protein in lung cancer

\begin{tabular}{|c|c|c|c|c|}
\hline \multirow[b]{2}{*}{ Characteristics } & \multirow[b]{2}{*}{$\mathbf{n}$} & \multicolumn{2}{|c|}{ CDK4 (\%) } & \multirow[b]{2}{*}{$P$} \\
\hline & & High expression & Low expression & \\
\hline \multicolumn{5}{|l|}{ Gender } \\
\hline Male & 59 & $30(50.8 \%)$ & $29(49.2 \%)$ & \\
\hline Female & 30 & 15(50\%) & $15(50 \%)$ & 1.000 \\
\hline \multicolumn{5}{|l|}{ Age(y) } \\
\hline$\geq 65$ & 39 & $21(53.8 \%)$ & $18(46.2 \%)$ & \\
\hline$<65$ & 50 & $24(48 \%)$ & $26(52 \%)$ & 0.671 \\
\hline \multicolumn{5}{|l|}{ Smoking } \\
\hline Yes & 38 & $23(60.5 \%)$ & $15(39.5 \%)$ & \\
\hline No & 51 & $22(43.1)$ & $29(56.9)$ & 0.135 \\
\hline \multicolumn{5}{|l|}{ Pathology classification } \\
\hline squamous cell carcinoma & 39 & $15(38.5 \%)$ & $24(61.5 \%)$ & \\
\hline adenocarcinoma & 46 & $17(40 \%)$ & $29(60 \%)$ & \\
\hline small cell undifferentiated carcinoma & 4 & $3(75 \%)$ & $1(25 \%)$ & $0.047^{*}$ \\
\hline \multicolumn{5}{|l|}{ Differentiated degree } \\
\hline High & 25 & $9(36 \%)$ & $16(64 \%)$ & \\
\hline middle & 34 & $21(61.8 \%)$ & 13(38.2\%) & \\
\hline Low or undifferentiated & 30 & $15(50 \%)$ & 15(50\%) & $0.150^{*}$ \\
\hline \multicolumn{5}{|l|}{ T classification } \\
\hline $\mathrm{T} 1+\mathrm{T} 2$ & 71 & $32(45.1 \%)$ & $39(54.9 \%)$ & \\
\hline $\mathrm{T} 3+\mathrm{T} 4$ & 18 & 13(72.2\%) & $5(27.8 \%)$ & 0.063 \\
\hline \multicolumn{5}{|l|}{ N classification } \\
\hline $\mathrm{N} 0+\mathrm{N} 1$ & 58 & $23(39.7 \%)$ & $35(60.3 \%)$ & \\
\hline $\mathrm{N} 2+\mathrm{N} 3$ & 31 & $22(71 \%)$ & $9(29 \%)$ & 0.007 \\
\hline \multicolumn{5}{|l|}{ Distant metastasis } \\
\hline Negative & 3 & $3(100 \%)$ & $0(0 \%)$ & \\
\hline Positive & 86 & $42(48.8 \%)$ & $44(51.2 \%)$ & 0.242 \\
\hline \multicolumn{5}{|l|}{ Clinical stage } \\
\hline $\mid \sim \|$ & 55 & $21(38.2 \%)$ & $34(61.8 \%)$ & \\
\hline $\mathrm{III} \sim \mathrm{IV}$ & 34 & $24(70.6 \%)$ & $10(29.4 \%)$ & 0.004 \\
\hline
\end{tabular}

*Kruskal Wallis Test.

smoking, degree of tumor differentiation, T/N/M classifications and clinical stages were also significantly correlated with patients' survival $(P=0.05, P=0.004, P=$ $0.018, P=0.003, P=0.039$, and $P<0.001$ respectively). To determine whether CDK4 is an independent prognostic factor for lung cancer, we performed multivariate analysis of CDK4 expression adjusted for the same parameters. The results indicated that the level of $C D K 4$ expression was an independent prognostic factor for lung cancer $(P<0.001)$ (Table 3$)$.

\section{Reduced CDK4 Expression Suppressed the Proliferation of} lung cancer cells in vitro

To study the biological function of CDK4, we used a lentiviral vector containing shRNA to specifically target and stably knock down the expression of CDK4 in A549 cells, a lung cancer cell line with high endogenous levels. Eight stably transfected cell clones were obtained (C1, C2, C3, C4, D1, D2, D3, D4) (Figure 2A). Real-time
PCR analysis showed that CDK4 mRNA expression in $\mathrm{C} 1, \mathrm{C} 2$, and D1 cells was markedly reduced compared to empty vector control clone A549 cells(PLV-Ctr). Further, decreased expression of $C D K 4$ protein was confirmed by western blotting in these three clones compared to PLV-Ctr and A549 cells(Figure 2B). C1 and D1 clones with significantly reduced $C D K 4$ protein expression were finally chosen for further experiments.

We examined the effect of decreased CDK4 expression on lung cancer cell growth in vivo. Using an MTT assay, we found that the parental lung cancer A549 cells had a similar growth rate as PLV-Ctr cells over a seven-day period, the growth of shRNA-CDK4 cells was significantly slower than the former two lines from day $3(\mathrm{P}<0.05)$ (Figure 2C). Interestingly, this result was also consistent in the plate clone formation test. Both the parental A549 cells and the PLV-Ctr cells formed a similar number of colonies on plate over a two-week period [(68 \pm 8.54$)$ vs. $(65 \pm 8.00)]$. In contrast, knocking down endogenous 
Table 3 Summary of univariate and multivariate Cox regression analysis of overall survival duration

\begin{tabular}{|c|c|c|c|c|c|c|}
\hline \multirow[b]{2}{*}{ Parameter } & \multicolumn{3}{|c|}{ Univariate analysis } & \multicolumn{3}{|c|}{ Multivariate analysis } \\
\hline & $P$ & HR & $95 \% \mathrm{Cl}$ & $P$ & HR & $95 \% \mathrm{Cl}$ \\
\hline \multicolumn{7}{|l|}{ Age } \\
\hline$\geq 65 \mathrm{vs} .<65$ years & 0.573 & 1.160 & $0.692-1.946$ & & & \\
\hline \multicolumn{7}{|l|}{ Gender } \\
\hline Male vs. female & 0.061 & 0.574 & $0.322-1.025$ & & & \\
\hline \multicolumn{7}{|l|}{ Smoking } \\
\hline Yes vs. No & 0.05 & 0.586 & 0.344-0.999 & 0.145 & 0.656 & $0.372-1.156$ \\
\hline \multicolumn{7}{|l|}{ Pathology classification } \\
\hline Squamous vs. Adenocarcinoma vs. Small cell undifferentiated & 0.883 & 1.036 & $0.648-1.656$ & & & \\
\hline \multicolumn{7}{|l|}{ Differentiation degree } \\
\hline High vs. Middle vs.Low & 0.004 & 1.660 & $1.176-2.343$ & 0.001 & 2.076 & $1.370-3.144$ \\
\hline \multicolumn{7}{|l|}{ T classification } \\
\hline$T_{1}-T_{2}$ vs. $T_{3}-T_{4}$ & 0.018 & 2.020 & $1.130-3.612$ & 0.609 & 0.819 & $0.381-1.759$ \\
\hline \multicolumn{7}{|l|}{ N classification } \\
\hline $\mathrm{N}_{0}-\mathrm{N} 1$ vs. $\mathrm{N}_{2} \mathrm{~N}_{3}$ & 0.003 & 2.259 & $1.323-3.860$ & 0.996 & 1.003 & $0.273-3.692$ \\
\hline \multicolumn{7}{|l|}{ M classification } \\
\hline$M_{0}$ vs. $M_{1}$ & 0.039 & 3.436 & $1.066-11.078$ & 0.088 & 3.666 & $0.825-16.293$ \\
\hline \multicolumn{7}{|l|}{ Clinical stage } \\
\hline I-II vs. III-IV & 0.000 & 2.586 & $1.515-4.412$ & 0.470 & 1.605 & $0.445-5.787$ \\
\hline \multicolumn{7}{|l|}{ CDK4 expression } \\
\hline High vs. Low * & 0.000 & 6.420 & $3.473-11.867$ & 0.000 & 6.714 & $3.329-13.451$ \\
\hline
\end{tabular}

CDK4 could dramatically reduce the number of colonies in $\mathrm{C} 1$ cells $(40 \pm 8.0)$ and $\mathrm{D} 1$ cells $(24.33 \pm 5.13)(\mathrm{P}<0.05)$ (Figure 2D).

\section{Knock-down of CDK4 Inhibited Migration and Cell Cycle Progression}

Cell migration is a key step during tumor development and metastasis. We tested the ability of A549 cells to migrate through the $8 \mu \mathrm{m}$ pores on the polycarbonate membrane, and found that the knock-down of endogenous CDK4 expression could significantly decrease cell migration of $C 1$ cells $(114 \pm 26.75)$ and D1 cells $(80 \pm 7.31)$ compared to the parental cells $(288.2 \pm 41.78)$ or PLV-Ctr cells $(254 \pm 34.28)(\mathrm{P}<0.05)$ (Figures $3 \mathrm{~A})$.

We measured the alteration of cell cycle progression after $C D K 4$ knock-down. Using flow cytometry analysis, we found that CDK4-deficient cells showed a significant increase in G1 phase population cells and a decrease in $\mathrm{S}$ phase cells compared to the PLV-Ctr and the parental A549 cells $(\mathrm{P}<0.05)$ (Figure $3 \mathrm{~B})$.

\section{CDK4 Inhibited the Expression of p21 in A549 cells}

The above results indicated that over-expression $C D K 4$ may play an important role in promoting the development of lung cancer. We further examined the effect of $C D K 4$ on the expression of key regulators of G1-S cell cycle transition including $C D K 1, C D K 2, C D K 6, C C N D 1, p 15, p 16$, $p 21$, and $p 27$. Real-time PCR indicated that reducing the levels of CDK4 significantly activates the expression of tumor suppressor $p 21$ by 3.12-fold(Figure 4A). Further, we measured the protein levels of $p 21$ in cells deficient of $C D K 4$ by western blot. CDK4-deficient cells had increased levels of $p 21$ protein compared to the parental A549 cells and cells expressing the control vector (Figure 4B). Our results suggest that $C D K 4$ may be involved in the development of lung cancer by antagonizing the effect of $p 21$.

\section{Discussion}

Lung cancer is a disease which consists of uncontrolled cell growth in tissues of the lung that may lead to metastases. These growths may ultimately contribute to the majority of the lung cancer deaths. However, the molecular mechanisms linking the initiation and development of lung cancer are not completely understood.

$C D K 4$ has gained prominence as a significant cancerrelated gene, as its function is to drive cell-cycle progression by phosphorylating the retinoblastoma protein. Overexpression of $C D K 4$ has been described in many tumors, including lung cancer.

In this investigation, we analyzed the expression of $C D K 4$ protein in lung cancer and normal lung tissues by immunohistochemistry. We found that CDK4 was mainly coexpressed in nucleus and cytoplasm in lung cancer tissues and predominantly expressed in cytoplasm in normal lung tissues. Furthermore, we presented evidence that CDK4 in nucleus and total protein levels was overexpressed in lung cancer tissues compared to normal lung tissues. Our reports were analogous to Wikman [5], Dobashi [6], and 


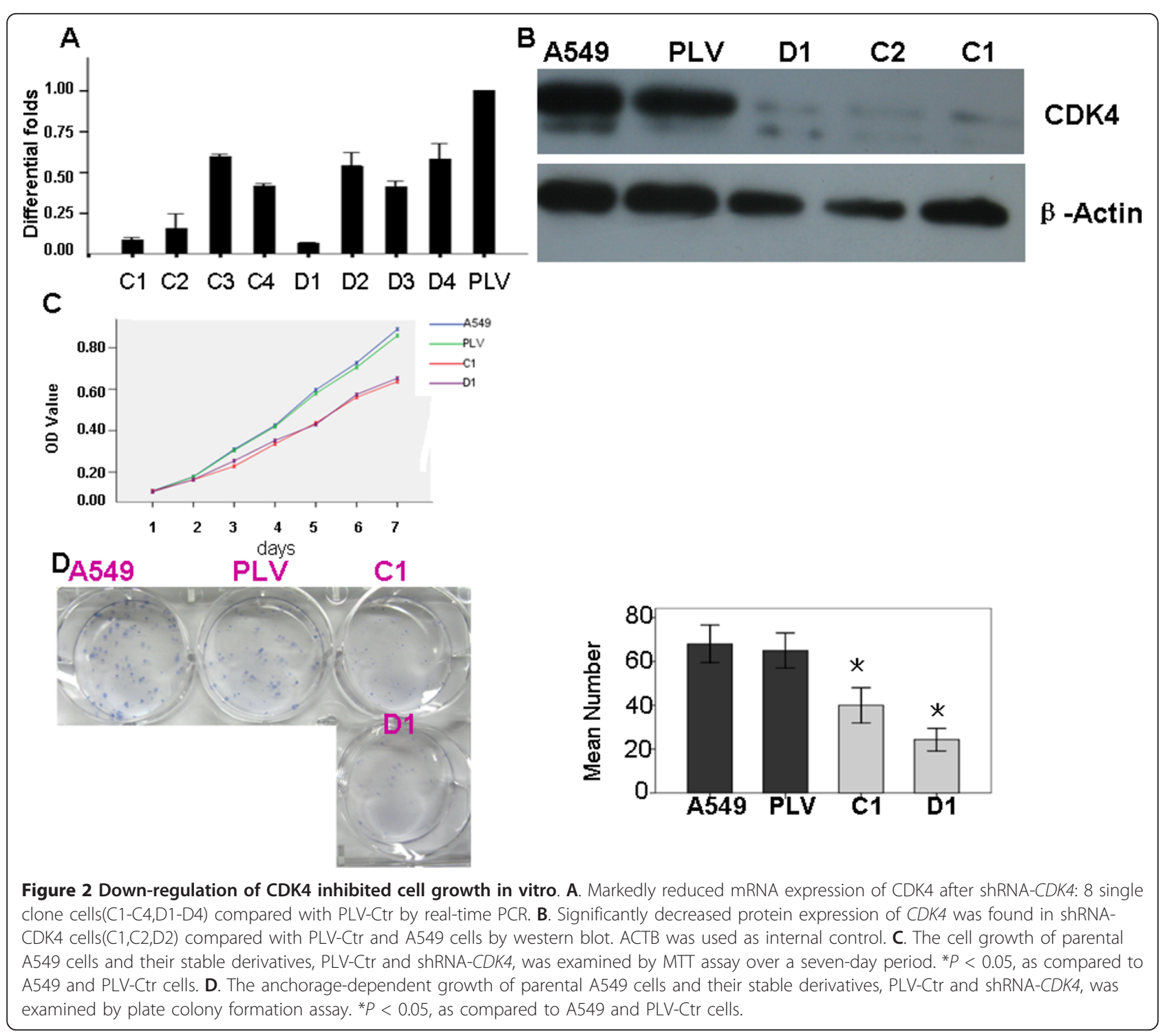

Lingfei [10] et al's results, suggesting that CDK4 participates in the pathogenesis of lung cancer.

$C D K 4$ is a protein kinase of the $C D K$ family that is important for cell cycle G1 phase progression, and its expression pattern is associated with clinical pathology parameters of lung cancer patients. Yoshida et al. found that $C D K$ was predominantly expressed in low-grade osteosarcomas compared to benign histological mimics, which suggested that $C D K 4$ can be a marker distinguishing low-grade osteosarcoma from benign mimics [11]. Zhang et al. reported that overexpression of CDK4 was positively correlated with Duke's stage of colorectal cancer [12]. In our study, we found that CDK4 overexpression was significantly correlated with the status of pathology classification, lymph node metastasis, and clinical stage of lung cancer patients. CDK4 appears to be more highly expressed in adenocarcinomas compared to the other two histologic subtypes. Similar to the report from Dobashi et al., we found that overexpression of $C D K 4$ was correlated with lymph node metastasis and statistically higher in the $\mathrm{N} 2 / \mathrm{N} 3$ group compared to the N0/N1 group [6]. In addition, overexpression of CDK4 was positively related to advanced disease status of lung cancer patients. Our results suggested CDK4 overexpression in lung cancer may accelerate tumor progression by promoting cell growth.

Further, we presented the evidence that $C D K 4$ protein expression in lung cancer was inversely correlated with patient's overall survival. Patients with higher expression of $C D K 4$ protein had an overall shorter survival time. According to univariate analysis, patient's overall survival is also inversely proportional to smoking, tumor 


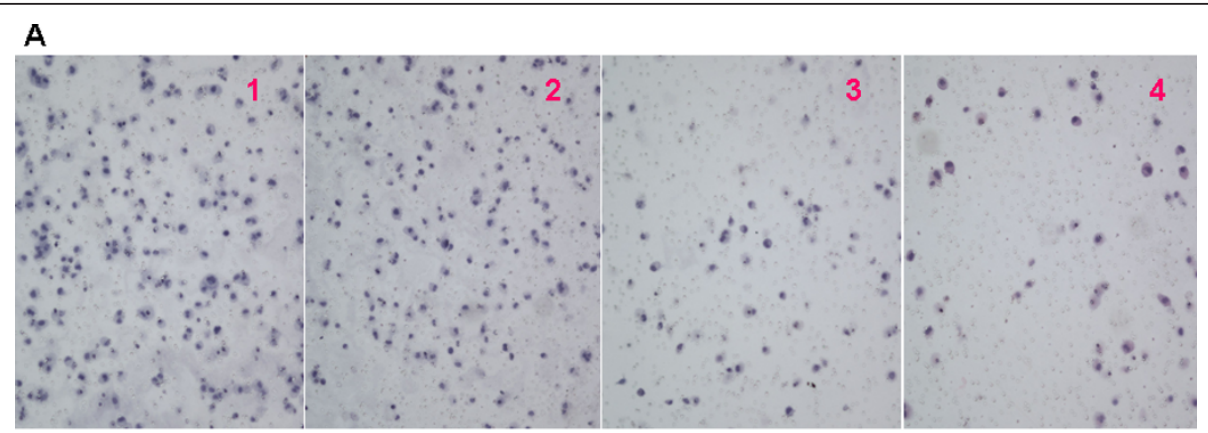

B

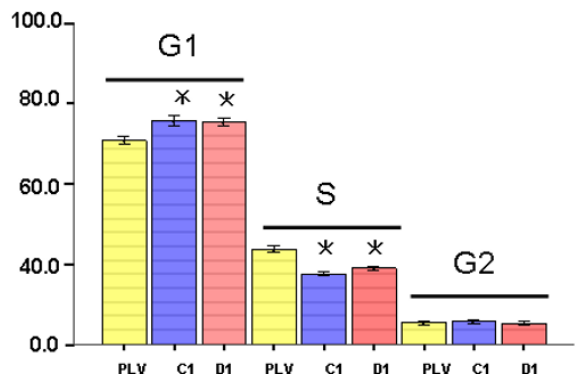

Figure 3 Reduced CDK4 expression inhibited cell migration and cell cycle progression in vitro. A: The migrating capability of parental A549 cells and their stable derivatives, PLV-Ctr and shRNA-CDK4, was examined by transwell and boyden chamber assay. B: Cell cycle profile was determined by FACS Caliber cytometry. Data were presented as mean \pm SD for three independent experiments. ${ }^{*} P<0.05$, as compared to PLVCtr and A549 cells.

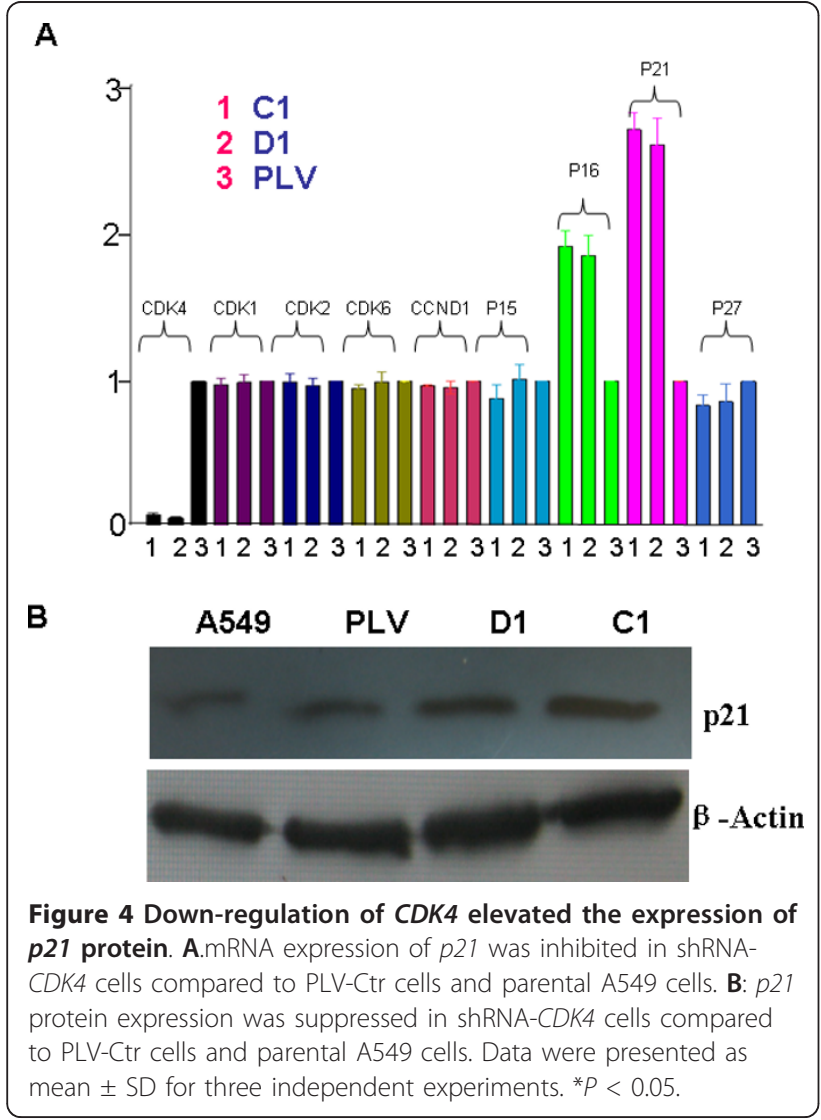

differentiated degree, and T/N/M classification. Multivariate analyses showed that increased expression of $C D K 4$ protein was a significant predictor of poor prognosis for lung cancer patients. Our reports were not consistent with Dobashi [6] and Ghazizadeh's results [13]. The discrepancy is most likely due to the different sample source, sample number, and evaluation method used. However, our results suggest CDK4 is a clinical significant biomarker for NPC prognosis.

In previous studies, overexpression of $C D K 4$ had been shown to promote cell proliferation by driving cell cycle progression [14-16]. To understand the biological functions of CDK4 in lung cancer, we employed a loss-offunction approach by knocking down the expression level of endogenous CDK4. To that end, we chose to use lung cancer A549 cell line which express high levels of endogenous CDK4 for our study. Similar to results published by Retzer-Lidl, An, and Rodriguez-Puebla et al. [14-16], we found that CDK4 plays a role in promoting cell proliferation and migration in vitro. Furthermore, we also found that inhibition of CDK4 could significantly retard the cell cycle transition from $\mathrm{G} 1$ to $\mathrm{S}$ phase. These results strongly support an oncogenic role for CDK4 in the development of lung cancer.

Based on the increased population of G1-S arrested cells after inhibiting CDK4 expression, we examined mRNA expression levels of relevant cell cycle factors. 
$C D K 1, C D K 2, C D K 6, C C N D 1, p 15, p 16, p 21$, and $p 27$ [17-21] were first examined in shRNA-CDK4 and control cells by real-time PCR. The results indicated that the reduction of endogenous $C D K 4$ expression markedly elevated the expression level of tumor suppressor $p 21$ ( $\geq 2$ folds). Further, we confirmed the upregulated protein expression of $p 21$ in CDK4-inhibited cells.

In summary, our results provide evidence that $C D K 4$ may be involved in the development of lung cancer. Furthermore, we also demonstrated that CDK4 could serve as a potential independent prognostic factor for lung cancer patients. Due to the limited sample size of patients in our investigation, further studies would be needed to verify these findings and establish the role of $C D K 4$ as a reliable clinical predictor for lung cancer outcome. Finally, our work is the first to present that $C D K 4$ mediates cell cycle progression by regulating the expression of $p 21$ expression in lung cancer.

\section{Acknowledgements}

Grants support: National 863 High Technology Research and Development program of China(No.2006AA02A404); Natural science fund of Guangdong Province (NO.8151051501000058)

\section{Author details}

${ }^{1}$ Cancer Research Institute of Southern Medical University, 510515, Guangzhou, PR China. ${ }^{2}$ Department of Respiratory Medicine, Affiliated Hospital of Guangdong Medical College, 524000, Zhanjiang, PR China. ${ }^{3}$ Department of Pathology, Medical College of Guangzhou, 510450, Guangzhou, PR China. ${ }^{4}$ School of Pharmacy, Guangdong Medical College, 523808, Dongguan, PR China. ${ }^{5}$ Cancer Center, Affiliated Hospital of Guangdong Medical College, 524000, Zhanjiang, PR China. ${ }^{6}$ Department of Bioinformatics, Southern Medical University, 510515, Guangzhou, PR China.

\section{Authors' contributions}

$A W, D W, J G, W L, H Y, Y Z, X L, H W$, and $Y Z$ performed this research. WF, ZL and $Z Y$ collected, analyzed, and interpreted data and wrote the manuscript. WF, ZL, and ZY supervised all the work. All authors have read and approved the final manuscript.

\section{Competing interests}

The authors declare that they have no competing interests.

Received: 27 December 2010 Accepted: 11 April 2011 Published: 11 April 2011

\section{References}

1. Houwen L: State of the art: lung cancer in China. Ann Thorac Cardiovasc Surg 2003, 9(3):147-148.

2. Miliani de Marval PL, Macias E, Conti CJ, Rodriguez-Puebla ML: Enhanced malignant tumorigenesis in Cdk4 transgenic mice. Oncogene 2004, 23(10):1863-1873.

3. Poomsawat S, Buajeeb W, Khovidhunkit SO, Punyasingh J: Alteration in the expression of cdk4 and cdk6 proteins in oral cancer and premalignant lesions. J Oral Pathol Med 2010, 39(10):793-799.

4. Lindberg D, Hessman O, Akerström G, Westin G: Cyclin-dependent kinase 4 (CDK4) expression in pancreatic endocrine tumors. Neuroendocrinology 2007, 86(2):112-118.

5. Wikman $H$, Nymark $P$, Väyrynen A, Jarmalaite $S$, Kallioniemi A, Salmenkivi K, Vainio-Siukola K, Husgafvel-Pursiainen K, Knuutila S, Wolf M, Anttila S: CDK4 is a probable target gene in a novel amplicon at 12q13.3-q14.1 in lung cancer. Genes Chromosomes Cancer 2005, 42(2):193-199.

6. Dobashi Y, Goto A, Fukayama M, Abe A, Ooi A: Overexpression of cdk4/ cyclin D1, a possible mediator of apoptosis and an indicator of prognosis in human primary lung carcinoma. Int J Cancer 2004, 110(4):532-541.

7. Fang W, Li X, Jiang Q, Liu Z, Yang H, Wang S, Xie S, Liu Q, Liu T, Huang J, Xie W, Li Z, Zhao Y, Wang E, Marincola FM, Yao K: Transcriptional patterns, biomarkers and pathways characterizing nasopharyngeal carcinoma of Southern China. J Transl Med 2008, 6:32.

8. Masunaga R, Kohno H, Dhar DK, Ohno S, Shibakita M, Kinugasa S, Yoshimura H, Tachibana M, Kubota H, Nagasue N: Cyclooxygenase-2 expression correlates with tumor neovascularization and prognosis in human colorectal carcinoma patients. Clin Cancer Res 2000, 6(10):4064-4068.

9. Liu Z, Li X, He X, Jiang Q, Xie S, Yu X, Zhen Y, Xiao G, Yao K, Fang W: Decreased expression of updated NESG1 in nasopharyngeal carcinoma: Its potential role and preliminarily functional mechanism. Int I Cancer 2010.

10. Lingfei $K$, Pingzhang $Y$, Zhengguo L, Jianhua G, Yaowu Z: A study on $p 16$, $\mathrm{pRb}, \mathrm{cdk} 4$ and cyclinD1 expression in non-small cell lung cancers. Cancer Lett 1998, 130(1-2):93-101.

11. Yoshida A, Ushiku T, Motoi T, Shibata T, Beppu Y, Fukayama M, Tsuda H: Immunohistochemical analysis of MDM2 and CDK4 distinguishes lowgrade osteosarcoma from benign mimics. Mod Pathol 2010, 23(9):1279-1288

12. Zhang LL, Zheng cq: Expression of p16 and CDK4 in colonic carcinoma and pericancerous mucose. Journal of Shenyang Medical College 2009, 11(2):74-76.

13. Ghazizadeh M, Jin E, Shimizu H, Fujiwara M, Arai S, Ohaki Y, Takemura T, Kawanami O: Role of cdk4, p16INK4, and Rb expression in the prognosis of bronchioloalveolar carcinomas. Respiration 2005, 72(1):68-73.

14. Retzer-Lidl M, Schmid RM, Schneider G: Inhibition of CDK4 impairs proliferation of pancreatic cancer cells and sensitizes towards TRAILinduced apoptosis via downregulation of survivin. Int I Cancer 2007, 121(1):66-75.

15. Rodriguez-Puebla ML, Miliani de Marval PL, LaCava M, Moons DS, Kiyokawa H, Conti CJ: Cdk4 deficiency inhibits skin tumor development but does not affect normal keratinocyte proliferation. Am J Pathol 2002, 161(2):405-411.

16. An HX, Beckmann MW, Reifenberger G, Bender HG, Niederacher D: Gene amplification and overexpression of CDK4 in sporadic breast carcinomas is associated with high tumor cell proliferation. Am J Pathol 1999, 154(1):113-118.

17. Cole AM, Myant K, Reed KR, Ridgway RA, Athineos D, Van den Brink GR, Muncan V, Clevers H, Clarke AR, Sicinski P, Sansom OJ: Cyclin D2-cyclindependent kinase $4 / 6$ is required for efficient proliferation and tumorigenesis following Apc loss. Cancer Res 2010, 70(20):8149-8158.

18. Larrea MD, Liang J, Da Silva T, Hong F, Shao SH, Han K, Dumont D, Slingerland JM: Phosphorylation of p27Kip1 regulates assembly and activation of cyclin D1-Cdk4. Mol Cell Biol 2008, 28(20):6462-6472.

19. Yu X, Luo Y, Zhou Y, Zhang Q, Wang J, Wei N, Mi M, Zhu J, Wang B, Chang H, Tang Y: BRCA1 overexpression sensitizes cancer cells to lovastatin via regulation of cyclin D1-CDK4-p21WAF1/CIP1 pathway: analyses using a breast cancer cell line and tumoral xenograft model. Int J Oncol 2008, 33(3):555-563.

20. Frizelle SP, Kratzke MG, Carreon RR, Engel SC, Youngquist L, Klein MA, Fourre L, Shekels LL, Kratzke RA: Inhibition of both mesothelioma cell growth and Cdk4 activity following treatment with a TATp16INK4a peptide. Anticancer Res 2008, 28(1A):1-7.

21. Braden WA, McClendon AK, Knudsen ES: Cyclin-dependent kinase $4 / 6$ activity is a critical determinant of pre-replication complex assembly. Oncogene 2008, 27(56):7083-7093, 27.

doi:10.1186/1479-5876-9-38

Cite this article as: Wu et al.: Elevated expression of CDK4 in lung cancer. Journal of Translational Medicine 2011 9:38. 